\title{
Developments in land use in a periurban area of central Portugal: the importance of biophysical parameters
}

\author{
R. L. Pato ${ }^{1}$, A. Tavares ${ }^{2}$ \& M. C. Magalhães ${ }^{1}$ \\ ${ }^{I}$ Department of Exact Sciences and Environment, School of Agriculture, \\ Polytechnic Institute of Coimbra, Portugal \\ ${ }^{2}$ Faculty of Sciences and Technology, Centre for Social Studies, \\ University of Coimbra, Portugal
}

\begin{abstract}
This study analyses the evolution of a rural/natural area into a periurban area, with reference to a small-scale hydrological basin close to the city of Coimbra, in Portugal, over the last half century (1958-2005). It involves a photointerpretation analysis using aerial images, together with field work carried out to record land use and human occupation between 1958 and 2005, based on the Corine Land Cover classification. Using a broad biophysical classification, the importance of biophysical parameters to changes in land use was verified. The results show that until the 1970s, geological and pedological variables determined forestry and agricultural land use. Subsequently, between 1979 and 1990, urban occupation and the building of infrastructures increased, but bore no relation to substratum properties. Whilst the basin has contrasting E-W biophysical characteristics, urban occupation has emphasised a N-S differentiation. The current lesser relevance of biophysical factors in relation to land use has increased local environmental vulnerabilities.
\end{abstract}

Keywords: land use, photointerpretation, biophysical parameters, hydrographical basin, urban expansion.

\section{Introduction}

Landscape evolution and changes in land use management are a consequence of complex interactions between environmental and socio-economic factors. The 
study of such dynamics is of crucial importance in understanding the relationship between anthropic occupation and land use, in order to enable us to anticipate future trends and to develop practices that promote the sustainable development of societies.

The increase in periurban areas is a challenge to developments in land use and resources management (Carvalho [1], Sousa et al [2]), and heavily determines local strategies and environmental qualification. An analysis of the processes of periurbanisation enables the trajectories of change to be assessed, inputs to be understood, and future conditions to be predicted, thus contributing towards better planning (Pan et al [3], Fu et al [4]).

Photointerpretation analysis using aerial images and GIS technology has improved the monitoring of developments in land use and the explanation of processes (Hietel et al [5], Hipple and Haithcoat [6]).

\section{General description of the area}

The area studied consists of a small-scale hydrological basin, approximately $7 \mathrm{~km}^{2}$ with a S-N orientation which lies close to the historic city of Coimbra in central Portugal.

The area has been characterised by profound changes in land use and occupation over the last half century. In the middle of the $20^{\text {th }}$ century it was a rural and natural area with some scattered urban areas or buildings along the major roads. It has since been developed into a periurban area with some well-defined urban cores and a discontinuous arrangement of buildings and infrastructures.

In administrative terms, it is partially divided into three parishes and currently has around 7,150 inhabitants according to the 2001 census INE [7], with local contrasts in population density ranging from $<25$ inhabitants $/ \mathrm{km}^{2}$ to over 9,900 inhabitants $/ \mathrm{km}^{2}$. At the start of the period under analysis, the resident population was approximately 2,500 .

Over the last fifty years and in particular during the period between 1960 and 1980, there has been a huge increase in the amount of residential buildings, mainly detached houses and, more recently, blocks of flats.

The area is served by health and school facilities, including a central hospital and four polytechnic schools, as well as an astronomical observatory and five historical monuments. It is also the site of a major pharmaceutical industry and is intersected by a main highway and railway.

The presence of the tertiary sector has increased in the area, whilst agricultural activities have declined.

From a physical point of view, the area is characterised by a sharply widening valley with hypsometry values ranging from $9 \mathrm{~m}$ to $200 \mathrm{~m}$, draining into the large floodplain of the River Mondego. Figure 1a provides a hypsometric representation of the asymmetric slopes of the valley, characterised by a concave western margin and an incised right margin framing an intermittent or ephemeral water stream. 


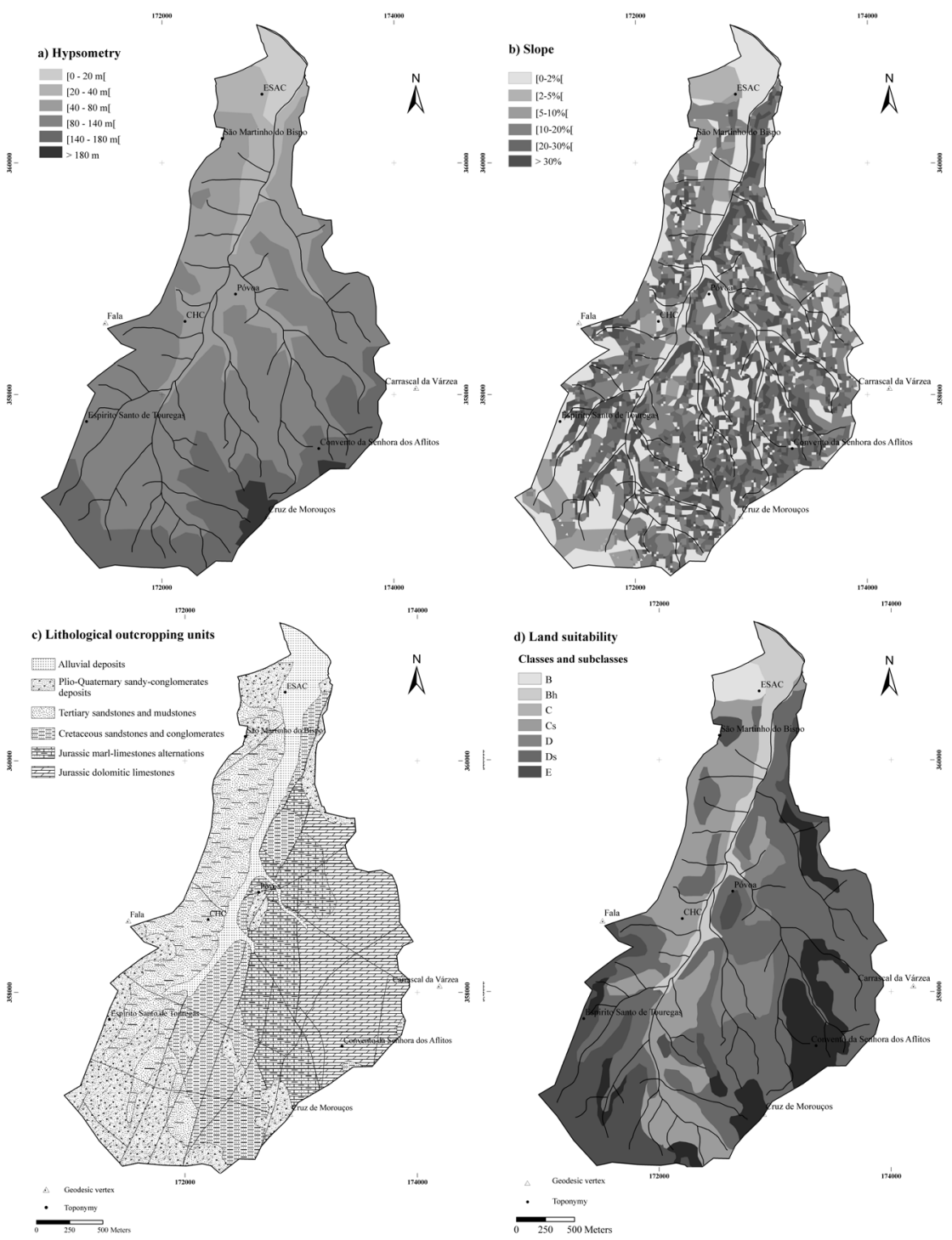

Figure 1: Biophysical characterization of the area: a) hypsometric representation; b) slope classification; c) lithological outcropping units; d) land suitability.

Figure $1 \mathrm{~b}$ illustrates the distribution of the slope classes, presenting average values ranging from $10 \%$ to $30 \%$, significantly affected by lithological factors (carbonate subtract) and tectonic lineaments, with a concentration of classes under $10 \%$ in upstream areas and in the downstream valley. 
Figure 1c represents the lithological units, with substratum Jurassic dolomitic and marl-limestone units on the eastern margin, Cretaceous and Tertiary sandstone, conglomerate and mudstone units, surface Plio-quaternary sandy-conglomerate deposits and alluvial deposits. Four major tectonic lineaments are recognized in the area (NNE-SSW, N-S, WNW-ESE, NE-SW), which are responsible for a general depressed structure to the west and a strong topographic outline, also leading to contrasting drainage density and infiltration rates.

Figure $1 \mathrm{~d}$ shows land suitability classes. Soils close to the stream are restricted by waterlogging during the winter season $(\mathrm{Bh})$, whilst the dominant classes $\mathrm{C}$ and $\mathrm{D}$ present limitations adversely affecting agricultural use due to the extreme shallowness of the soil.

The area has the characteristics of a moist Mediterranean climate, with more than $60 \%$ of precipitation falling between November and March. The average annual temperature is $15.5^{\circ} \mathrm{C}$, with a maximum thermal amplitude of $14^{\circ} \mathrm{C}$ in August. The main hydrological input comes from annual precipitation, with annual average values close to $900 \mathrm{~mm}$. Approximately $50 \%$ is consumed in evapotranspiration.

\section{Methods and techniques}

Approaches to climate, morphology, geology, structure and soil occupation were mainly supported by the available bibliography, thematic maps (Tavares [8], Tavares and Cunha [9], Pato [10]) and aerial photography, as well as fieldwork. Demographic parameters and socio-economic characteristics were processed from official data, namely the five census surveys carried out during the period 1950-2001.

A spatial-temporal database which included layers of land cover and environmental variables was developed using GIS software.

The first level outcropping representation of biophysical parameters was produced, cross-referenced and analysed in terms of previous cartography.

A photointerpretation analysis was carried out, using aerial images with original scales varying from 1:10 000 to 1:26 000, showing land use in 1958, 1973, 1979, 1990, 1995 and 2005. For this analysis, the Corine Land Cover classification was used.

The contrasted imaging analysis provided a first level of selection, showing built-up, agricultural, forestall and natural areas. A second level of classification, supported by field work and in situ validation identified, on a year-by-year basis, the continuous urban fabric, discontinuous urban fabric, road network, health and education facilities, arable lands, permanent crops, dry and irrigated meadows, hardwood, softwood, mixed forest areas, natural areas with shrub and herbaceous associations, base soil, and areas damaged by fire.

Data analysis, classification and mapping were carried out using ArcGIS 9.1 ${ }^{\circledR}$.

\section{Changes in land use and occupation}

The first four aerial images with panchromatic data needed frequent validation using contemporary oral, cartographic and written references. 
Figure 2a shows basin land use and occupation in 1958. Representation by classes shows a large area with standing crops and an important mixed forest area upstream. Urban occupation is divided into eleven polygons, with the vast majority of the restricted discontinuous urban fabric located in watershed areas.

Arable lands are associated with alluvial deposits and the distribution of permanent crops was clearly related to the Jurassic carbonate units, supporting non-intensive olive tree cultivation. It also can be seen that natural areas with shrub and herbaceous associations are located, in particular, in the middle of the basin, supported by sedimentary sandstones and conglomerates.

The Figure $2 \mathrm{~b}$ represents occupation in 2005 , denoting the profound changes that have taken place since 1958. The arrangement of the polygons is highly complex and urban areas have expanded, particularly in the middle of the basin.

The 2005 natural colour imagery shows a large amount of land occupied by hardwoods in the upstream valley. An association between the discontinuous urban fabric and natural areas with shrub and herbaceous associations can also be observed, thus identifying areas under urban pressure.

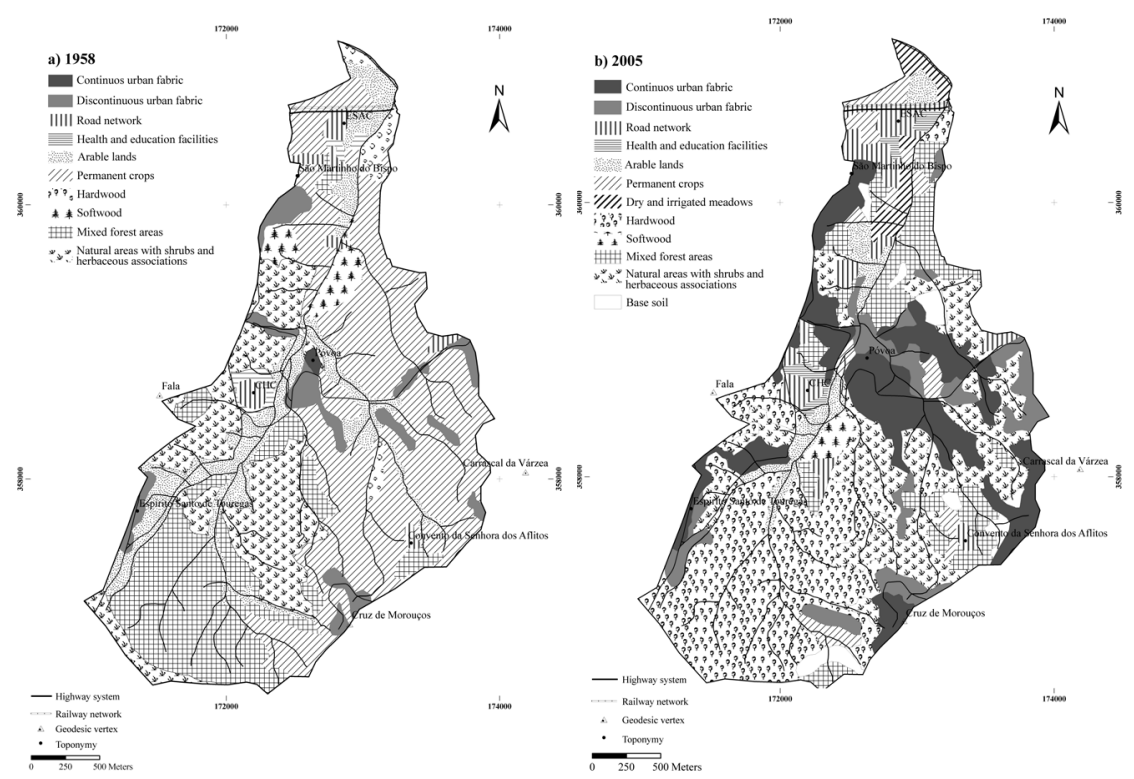

Figure 2: $\quad$ Land use and occupation in the area, from imagery classification in a) 1958 and b) 2005 .

Table 1 shows the evolution of land use and occupation in the basin, represented by an analysis of the years 1958, 1973, 1979, 1995 and 2005. The number of polygons and the area occupied by each class shows a generalised increased complexity of patches. The analysis also indicates a consistent amount of continuous urban fabric and a reduction in arable land and permanent crops. 
Table 1: Number of patches and areas for each type of land use and occupation, according to the Corine Land Cover classification.

\begin{tabular}{|c|c|c|c|c|c|c|c|c|c|c|c|c|}
\hline \multirow[t]{2}{*}{ Classes } & \multicolumn{6}{|c|}{ Patch $\left(\mathrm{N}^{\circ}\right)$} & \multicolumn{6}{|c|}{ Area $\left(\mathrm{km}^{2}\right)$} \\
\hline & 1958 & 1973 & 1979 & 1990 & 1995 & 2005 & 1958 & 1973 & 1979 & 1990 & 1995 & 2005 \\
\hline Continuos urban fabric & 1 & 4 & 4 & 4 & 6 & 9 & 0,015 & 0,308 & 0,361 & 0,586 & 0,947 & 1,204 \\
\hline Discontinuous urban fabric & 11 & 5 & 8 & 10 & 9 & 10 & 0,412 & 0,356 & 0,551 & 0,786 & 0,554 & 0,528 \\
\hline Road network & 7 & 9 & 10 & 11 & 8 & 10 & 0,151 & 0,194 & 0,222 & 0,323 & 0,423 & 0,406 \\
\hline Health and education facilities & 3 & 3 & 4 & 3 & 3 & 3 & 0,073 & 0,079 & 0,063 & 0,053 & 0,087 & 0,082 \\
\hline Arable lands & 6 & 8 & 4 & 4 & 3 & 3 & 0,861 & 0,513 & 0,358 & 0,301 & 0,246 & 0,292 \\
\hline Permanent crops & 6 & 11 & 9 & 9 & 12 & 10 & 2,719 & 1,880 & 1,641 & 1,040 & 0,606 & 0,286 \\
\hline Dry and irrigated meadows & _ & _ & _ & 2 & 3 & 3 & _ & - & & 0,114 & 0,137 & 0,165 \\
\hline Hardwood & 3 & 3 & 3 & 5 & 7 & 4 & 0,133 & 0,105 & 0,089 & 2,197 & 1,238 & 1,922 \\
\hline Softwood & 2 & 3 & 3 & 2 & 1 & 1 & 0,179 & 0,597 & 0,356 & 0,197 & 0,070 & 0,076 \\
\hline Mixed forest areas & 8 & 6 & 7 & 10 & 8 & 10 & 1,303 & 2,463 & 2,986 & 0,508 & 0,983 & 0,719 \\
\hline $\begin{array}{l}\text { Natural areas with shrubs and } \\
\text { herbaceous associations }\end{array}$ & 6 & 6 & 4 & 7 & 10 & 12 & 1,204 & 0,477 & 0,309 & 0,894 & 0,675 & 1,196 \\
\hline Base soil & _ & 2 & 2 & 1 & 3 & 7 & _ & 0,080 & 0,115 & 0,052 & 0,087 & 0,174 \\
\hline Areas damaged by fire & & & & & 1 & & & & & & 0,983 & \\
\hline Total & 53 & 60 & 58 & 66 & 71 & 82 & & & & & & \\
\hline
\end{tabular}

The different forest areas reveal contrasting developments during this period which, in the case of some classes such as dry and irrigated meadows and areas damaged by fire, are restricted in time.

Developments in land use between 1958 and 2005 reflect major internal and external inputs, such as the three municipal master plans, the implementation of restrictions in the form of environmental and agricultural legal instruments, the construction of important health and education facilities, the densification of road infrastructures, urban pressure and proximity to commercial facilities and a large forest fire.

Figure 3 represents the subclass evolution of the basin during the period under analysis, showing an increase in artificial areas as opposed to natural and agro-forest areas. The continuous expansion of urban areas and the reduction in areas covered by permanent crops is also evident.

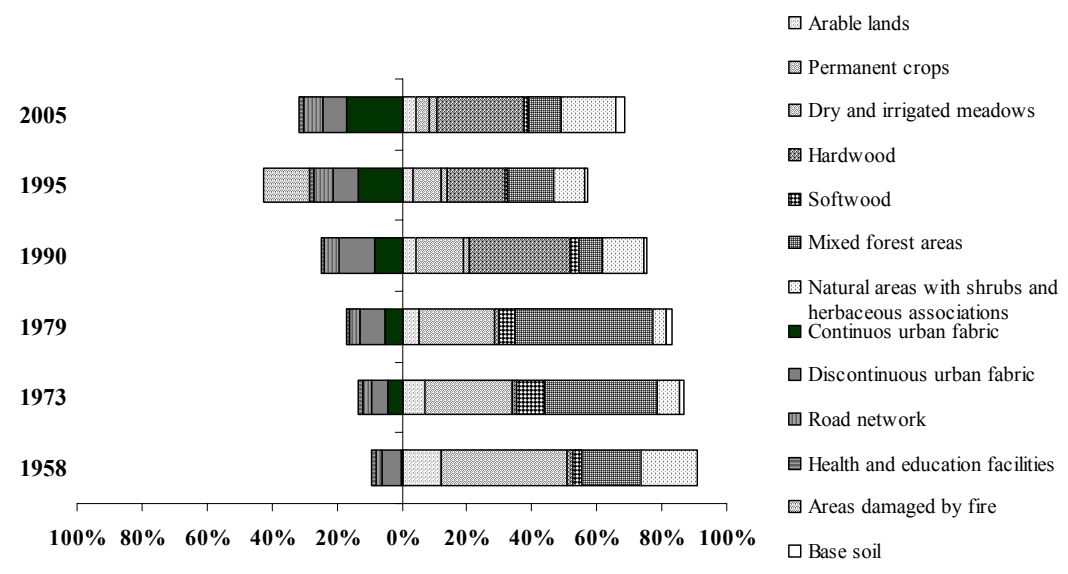

Figure 3: $\quad$ Subclass evolution in land use and occupation for the period under analysis (1958-2005). 
The results show that urban occupation gradually increased from 1958 and was particularly significant in the middle of the basin, mainly replacing agricultural areas.

A general reduction in agricultural areas of about $40 \%$ can be observed between 1958 and 2005. In contrast, forest and natural areas increased by approximately $18 \%$ (Table 2 ). A fire episode affecting forest and natural vegetation was identified in the 1995 imagery.

The hydrographic basin still reveals predominantly forest and urban forms of occupation, with reference to the upstream area and the middle of the basin respectively. However, major changes have occurred in the intermediate part of the area under study as a result of urban consolidation and the growth of periurban areas. The building of facilities and road infrastructures has underpinned periurban growth.

The temporal transformation matrix presented in Table 2 highlights the main dynamics of the periods under analysis, showing distinct transformation phases.

The major changes affecting agricultural and forest areas occurred during the period 1958-1973, with contrasting results. The period 1973-1990 revealed a more stable dynamic for changes in land use. The changes evident after analysis of the 1990 imagery show that the greatest variations took place in forest areas or open spaces with little or no vegetation, which were the precursors of the processes of urbanization.

Table 2: $\quad$ Proportional changes in land use (\%) in the area.

\begin{tabular}{|c|c|c|c|c|c|c|}
\hline Classes & \multicolumn{4}{|c|}{$(\%)$} & 1995-2005 & $\begin{array}{c}1958-2005 \\
(\%)\end{array}$ \\
\hline Artificial surfaces & 4,1 & 3,7 & 7,8 & 3,8 & 2,9 & 22,3 \\
\hline Agricultural areas & $-16,9$ & $-5,5$ & $-7,8$ & $-6,5$ & $-3,6$ & $-40,3$ \\
\hline Forest areas & 11,6 & 1,4 & 0,8 & $-11,7$ & 13,4 & 15,5 \\
\hline Natural areas & 1,1 & 0,5 & $-0,9$ & 14,5 & $-12,7$ & 2,5 \\
\hline
\end{tabular}

The analysis also indicated a continuous increase in artificial areas, showing that the trajectories of land use associated with artificial surfaces were supported by the existing urban nucleus and infrastructures. Agricultural use was mainly replaced by an increase in artificial surfaces and this change essentially occurred in the eastern part of the area.

Agricultural areas were also replaced by forests and natural areas with shrub and herbaceous associations in the upstream basin.

An analysis of the period spanning roughly 50 years shows that urban growth took place essentially in areas used for agriculture, representing $73 \%$ of the total.

\section{Conclusions}

The study reveals landscape developments and the dynamics of change relating to land use and occupation during the period under analysis. Urban areas have expanded, with the largest urban area growth taking place during the period 
between 1979 and 1990. It began with the transformation of areas containing standing crops and mixed forest areas into areas with a discontinuous urban fabric. During the 1990s there was a substantial movement from a discontinuous to a continuous urban fabric.

Agricultural areas were substantially transformed into artificial surfaces or forest areas, specifically upstream of the basin.

An analysis of developments in land use and occupation shows the different forms of interaction with biophysical parameters. Before 1979, geological and pedological variables determined the use of land for forestry and agricultural purposes. After that, a positive evolution in forest areas, namely hardwoods, took place within hypsometric classes above $40 \mathrm{~m}$, slope classes over $20 \%$ with a Jurassic or Cretaceous substratum, and in C, D and E land suitability soil classes.

Subsequently, between 1979 and 1990, urban occupation and the building of infrastructures increased, but bore no relation to substratum properties. The main examples of built-up areas are supported by Jurassic carbonate units in hypsometric ranges between $40 \mathrm{~m}$ and $180 \mathrm{~m}$.

Whilst the basin has contrasting E-W biophysical characteristics, the progressive urban occupation has emphasised a N-S differentiation. The lesser relevance of biophysical factors in relation to land use nowadays has increased local environmental vulnerabilities, reflected in the inadequate use of soils and hydrological resources, the use of units with lower geotechnical characteristics, and an increase in natural hazards such as flooding, mass movement and wildfires.

\section{References}

[1] Carvalho, J., Formas urbanas, Minerva Coimbra: Coimbra, Portugal, 148 p., 2003.

[2] Sousa, L.; Galante, H.; Batel, A. \& Hespanha, P., Observing cities. Social inequalities: A cartographic case study of Aveiro, Portugal. Cities, Vol. 20, 4, pp. 241-252, 2003.

[3] Pan, D.; Domon, G.; de Blois S. \& Bouchard, A., Temporal (1958-1993) and spatial patterns of land use changes in Haut-Saint-Laurent (Quebec, Canada) and their relation to landscape physical attributes. Landscape Ecology, 14, pp. 35-52, 1999.

[4] Fu, Bo-Jie; Zhang, Qiu-Ju; Chen, Li-Ding; Zhao, Wen-Wu; Gulinck, H.; Liu, Guo-Bin; Yang, Qin-Ke \& Zhu, Yong-Guan, Temporal change in land use its relationship to slope degree and soil type in a small catchement on the Loess Plateau of China. Catena, 65, pp. 41-48, 2006.

[5] Hietel, E.; Waldhardt, R. \& Otte, A., Analysing land-cover changes in relation to environmental variables in Hesse, Germany. Landscape Ecology, 19, pp. 473-489, 2004.

[6] Hipple, J.D. \& Haithcoat, T.L., Remote sensing in urban infrastructure and business geographics. in Remote Sensing, ed. S. Aronoff, ESRI Press: Redlands, California, pp. 405-413, 2005. 
[7] INE, XIV Recenseamento Geral da População e IV Recenseamento Geral da habitação, Instituto Nacional de Estatística: Lisboa, Portugal, 2001.

[8] Tavares, A.O., Condicionantes Físicas ao Planeamento. Análise da susceptibilidade no espaço do concelho de Coimbra. Ph.D. Thesis, Universidade de Coimbra, Portugal, 346 p, 1999.

[9] Tavares, A.O. \& Cunha, L., Espaços de planeamento no concelho de Coimbra. A importância das variáveis biofísicas, demográficas e sociais Cadernos de Geografia, 21/23, FLUC, Coimbra, Portugal, pp. 241-254, 2002/04.

[10] Pato, R.L., Bacia hidrográfica da ribeira dos Covões. Variáveis biofísicas e evolução do uso do solo no período 1958-2002. MSc. Thesis, Universidade de Coimbra, Portugal, 201 p, 2007. 